Motrivivência Ano XXII, No 34, P. $72-86$ Jun./2010

DOI:10.5007/2175-8042.2010n34p72

\title{
REFLEXÕES SOBRE A IMAGEM E A FOTOGRAFIA: possibilidades na pesquisa e no ensino da Educação Física
}

\author{
Mariana Mendonça Lisboa? \\ Giovani De Lorenzi Pires²
}

\begin{abstract}
Resumo
Partindo de contribuições teóricas como as de Guy Debord e Susan Sontag para o entendimento crítico da realidade mediada por imagens, pretendemos refletir ao longo deste

artigo, algumas possibilidades de se trabalhar com imagens em processos educativos e na pesquisa, especialmente na Educação Física. É possível usá-las? Com que interesses? Como a fotografia pode ser potencializada e pensada teoricometodologicamente em práticas educativas e científicas comprometidas com mudanças sociais? São as principais reflexões realizadas em
\end{abstract}

\begin{abstract}
Starting this reflexion from the theoretical contributions such as Guy Debord and Susan Sontag to have a critical understanding of our reality, mediated by images, we intend, throughout this article, to reflect to the reader, some ability to think and work at school with images in educational processes and research, especially Physical Education. Is it possible their use? What can be the interests? How of photography can be enhanced and theoretical-methodologically thought over the educational and scientific practices that have com-
\end{abstract}

1 Mestre em Educação Física (PPGEF/CDS/UFSC). Professora da Faculdade Metropolitana de Blumenau (FAMEBLU/SC), Curso de Educação Física. Professora de Educação Física da Prefeitura de Florianópolis (PMF/SC). Contato: marianaml_floripa@hotmail.com.

2 Doutor em Educação Física (UNICAMP). Professor do Departamento de Educação Física (DEF/ UFSC) e Programa de Pós-Graduação em Educação Física (PPGEF/UFSC).

Contato: giovanipires@cds.ufsc.br. 
diálogo com outros trabalhos da área, que deixamos como desafio a ser assumido por pesquisadores/ professores, em contraposição ao Mundo-Imagem, à banalização da imagem, sobretudo a fotográfica.

Palavras-chave: Imagem, Fotografia, Pesquisa e Ensino, Educação Física. mitment with social changes? These are the main considerations that we give as a challenge to be assumed by researchers/teachers.

Key Words: Image, Photography, Research and Teaching, Physical Education.

\section{Reflexões iniciais}

Vivemos num mundo onde cada vez mais as imagens bombardeiam nosso cotidiano, instaurando modificações principalmente em nossa percepção da realidade. Basta ligarmos a televisão, folhearmos uma revista ou jornal, sairmos pelas ruas e uma enxurrada de imagens estará disponível vendendo mercadorias e sonhos, "comprovando" a realidade, fornecendo representações e informações de como devemos nos vestir, do que devemos comer, enfim... de como devemos ser e agir. É quase impossível não conviver na "Sociedade do Espetáculo" (DEBORD, 1997) ou no "Mundo Imagem" (SONTAG, 2004), com a presença íntima e familiar dos simulacros e ícones da modernidade.

As imagens, flashes de realidades e artificialidades, espalhamse no cotidiano social tecendo uma trama de visibilidade e espetacularidade jamais vista. Com os avanços e hibridizações tecnológicas, aliados a popularização de bens culturais, é comum observamos as diferentes formas de banalização e uso indiscriminado das imagens, especialmente as fotográficas, que são agora produzidas (e reproduzidas em série) pelas câmeras digitais e multitelas.

Mas como compreender esse cenário social apontado, que tem a primazia da imagem? Existem possibilidades de se utilizar imagens fotográficas de forma crítica e reflexiva em processos pedagógicos e de pesquisa? Como o uso da fotografia pode ser potencializado e pensado, teorico-metodologicamente, em práticas educativas e científicas comprometidas com mudanças sociais?

Partindo de contribuições teóricas como as de Guy Debord e Susan Sontag para o entendimento crítico da nossa realidade mediada por imagens, pretendemos refletir sobre algumas possibilidades de se trabalhar com imagens em processos educativos e na pesquisa, 
especialmente na Educação Física. Isto porque acreditamos não ser possível, nem desejável, negarmos o potencial crítico e educativo das imagens e dos recursos tecnológicos (vídeo, fotografia, etc.). Contudo, também não queremos aqui celebrar e incentivar a utilização indiscriminada da imagem de forma não responsável. Sem cair em visões "apocalípticas" ou "integradas" $(E C O, 1984)$ frente aos meios de comunicação e recursos tecnológicos, queremos dialeticamente pensar nos limites e possibilidades da imagem como instrumento e método de pesquisa, e também a sua inserção na escola como uma demanda emergente.

Para compor este ensaio, iremos agregar às reflexões teóricas referidas algumas experiências de pesquisa/intervenção no âmbito da Educação Física/Ciências do Esporte, realizadas por professores/ pesquisadores do LABORATÓRIO DOS AUTORES 3 .

Nossa expectativa, é claro, não é de esgotar o assunto, mas sim, de maneira introdutória, suscitar "pistas" que criem condições para ultrapassar métodos pedagógicos e de pesquisa que não percebem o potencial dos recursos imagéticos e, por isso, não levam em conta a linguagem audiovisual, o vídeo, a fotografia, e a educação para uma leitura crítica de imagens, como uma forma de criar "resistências" e "possibilidades" criativas, críticas e reflexivas (quem sabe até subversivas?) frente a essa realidade.

\section{Uma sociedade mediada por imagens}

No presente estágio social, observa-se a espetacularização da sociedade, processo muito bem explicitado por Guy Debord ainda na década de 60 , ao fazer uma análise crítica da moderna sociedade do consumo, onde se verifica fortemente a tirania das imagens e a submissão alienante ao império da mídia (DEBORD, 1997).

Nesta perspectiva, ocorre uma autonomização das imagens, que passam a ser consumidas como referenciais de identificação do indivíduo reificado, ou seja, as imagens tornam-se um espelho espetacular de sua vida danificada e uma representação do mundo à sua volta traduzido sob o espetáculo: "quando o mundo real transforma-se em simples imagens, as simples imagens tornam-se seres reais e motivações eficientes de um comportamento hipnótico" (DEBORD, 1997, p.18).

3 Os autores integram o Laboratório e Grupo de Pesquisa Observatório da Mídia Esportiva da Universidade Federal de Santa Catarina. Sobre o grupo, ver em www.labomidia.ufsc.br. 
Em sua primeira tese, Debord (1997, p. 13) afirma que "toda a vida das sociedades nas quais reinam as modernas condições de produção se apresenta como uma imensa acumulação de espetáculos. Tudo que era vivido diretamente tornou-se uma representação." Parafraseando Marx, em O Capital, o autor situa o espetáculo dentro da lógica do projeto e modo de produção capitalista, que transforma em mercadoria (agora imagem-objeto) a cultura e setores da vida social. Enraizada na produção humana enquanto mercadoria a Sociedade do Espetáculo está organizada num nível mais elevado, em que o objeto material puro e simples dá lugar a imagens-objetos valorizadas, consumidas e contempladas.

Não mais compreendidas como produto social do trabalho humano, as mercadorias, potencializadas pelas imagens espetacularizadas, passam a existir carregadas de faculdades intrínsecas (significados e valores), transferíveis (via consumo), ou desejadas (via contemplação). Assim, vendem-se sonhos, estilos de vida, qualidades subjetivas, etc. através da suposta representação.

A degradação da vida social pela economia, que levou à valorização do TER sobre o SER, sofre agora nesta fase espetacular um deslizamento generalizado do TER para o PARECER. Nesse sentido a cultura da imagem notabiliza-se e adquire reconhecimento social, pela importância dada à visibilidade e aparência, em detrimento das experiências humanas formativas.

Em texto mais recente, Kehl (2004) acredita haver uma passagem do conceito de Indústria Cultural ${ }^{4}$ para o de Sociedade do Espetáculo não enquanto uma mudança ou ruptura de paradigma, mas uma conseqüência e desenvolvimento daquela "indústria", por intermédio da mais poderosa mídia: a televisão. Para Kehl (2004, p. 44), "da indústria cultural à sociedade do espetáculo, o que houve foi um extraordinário aperfeiçoamento técnico dos meios de traduzir a vida em imagem, até

4 A expressão Indústria Cultural foi cunhada por Horkheimer e Adorno na década de 40 em seu exílio norteamericano e publicada posteriormente em Dialética do Esclarecimento no ano de 1947 (ADORNO; HORKHEIMER, 1985). Consiste numa crítica ao modo de produção da cultura contemporânea, e se colocava em oposição ao termo até então usado cultura de massa, porque este poderia levar ao falso entendimento de se tratar de uma cultura feita pelo povo, quando na verdade tratava-se de uma cultura feita para o povo (as massas). Adorno e Horkheimer constataram naquela época o processo de banalização/rebaixamento da produção e difusão cultural enquanto mercadoria, surpreendendo-se com o estágio de integração da cultura e da arte ao sistema capitalista da produção de bens materiais, ou seja, a cultura resumindo-se em mercadoria dotada de valor de troca, produzida e consumida de forma massiva e indiferenciada (PIRES, 2002). 
que fosse possível abarcar toda a extensão da vida social".

Cabe destacar que não apenas os bens culturais materiais sofrem essa espetacularização enquanto imagem-objeto, mas a própria realidade social (vida real) que passa a ser cada vez mais representada pelas imagens dos meios de comunicação, especialmente a TV, bem como as relações sociais sofrem essa influência. Conforme afirma Debord (1997, p. 14), "o espetáculo não é um conjunto de imagens, mas uma relação social entre pessoas, mediada por imagens".

Em um estudo a que chamou de micro-etnografias, Bitencourt (2009) discorre sobre a banalização da fotografia, como consequência do advento da câmera digital. Observando o comportamento de torcedores em eventos esportivos espetacularizados, realizados em Madrid (futebol, tênis e corrida de touros), o autor reflete que os aficionados "tomam a imagem como base de sua relação com o vivido. Não basta estar presente, é preciso levar a presença consigo; é preciso arrastar a memória através das imagens, mas não qualquer imagem, mas sim aquela que anuncia - ou denuncia - como prova, a de se ter estado lá".

Em seu relato, Bitencourt fala da procura ávida dos fãs por imagens "pessoais" dos seus ídolos, mesmo que milhares de fotografias estejam disponíveis na internet. Com as suas imagens "clicadas", tomadas como verdadeiros troféus pelos torcedores, os atletas passam a fazer parte de arquivos pessoais. Melhor ainda (para os torcedores) é se a sua própria presença puder ser registrada na fotografia, em primeiro plano, com o ídolo no fundo. Cabe perguntar quem é, na verdade, o "protagonista" daquela imagem?

Numa perspectiva também crítica em relação à sociedade moderna, em virtude de sua submissão e obsessão pelas imagens, encontramos as reflexões de Sontag (2004), direcionadas principalmente à fotografia. No início de um de seus ensaios, ela já nos trás a afirmativa tese de Feuerbach para quem a nova era "prefere a imagem à coisa, a cópia ao original, a representação à realidade, a aparência ao ser" (p.169). Assim, acredita que o mundo-real está sendo substituído pelo mundo-imagem, ou seja, a realidade cada vez mais se torna imagens, simulacros a serem consumidos:

Imagens que têm poderes excepcionais para determinar nossas necessidades em relação à realidade e são, elas mesmas, cobiçados substitutos da experiência em primeira mão se tornando indispensáveis para saúde da economia, para a esta- 
bilidade do corpo social e para a busca da felicidade privada (SONTAG, 2004, p, 170).

Nesta perspectiva, tudo existe para ser representado em fotografia/imagem. A verdade não é mais o fato em si, mas sim as várias fotografias/imagens produzidas, mostrando o quanto nossa concepção e percepção da realidade é imagética; imagens, vídeos, fotos, é que dão os significados as coisas e ao que somos. Isto acaba tornando a imagem mais real que o próprio real, e a realidade é cada vez mais aquilo que as câmeras mostram. Um exemplo disso é a cotidiana expressão "parecia filme, coisa de cinema!" para se referir a qualidade de realidade existente em determinadas experiências (SONTAG, 2004).

Numa Sociedade do Espetáculo, em que a Indústria Cultural tem na mídia os seus principais agentes, torna-se necessário para a manutenção de ideologia do capital produzir necessidades, desejos, sonhos que se revestem em imagens a serem consumidas, como promessa de felicidade em meio às dificuldades da vida danificada.

Ainda neste sentido ideológico da produção de imagens, Sontag (2004, p.195) afirma que "as câmeras definem a realidade de duas maneiras essenciais para o funcionamento de uma sociedade industrial avançada: como espetáculo (para as massas) e como um objeto de vigilância (para os governantes)."

Ter consciência dessa realidade é fundamental para pensarmos em condições de transformações, em possibilidades de esclarecimento e emancipação do sujeito. Nesta perspectiva, vemos dois caminhos de intervenção: como educadores, no trabalho pedagógico-educativo com os alunos receptores/consumidores dessas imagens, e através de pesquisas reflexivas frente às imagens das mídias em geral e/ou com a utilização dos instrumentos tecnológicos potencializadores de textos visuais.

\section{A imagem/ fotografia na pesquisa}

Historicamente, as formas de produção e socialização de conhecimentos científicos vêm sendo atribuídas quase que exclusivamente ao mundo letrado, à excelência e objetividade (que hoje soa como um positivismo) do texto escrito. Sem cair na lógica do mundo-imagem, mas apropriandose criticamente de conhecimentos produzidos pelo homem através dos avanços tecnológicos (vídeo, fotografia, etc.), e dando-lhes um rigor epistemológico necessário, acreditamos ser este um elemento qualificador da pesquisa, isto é, a 
articulação do texto visual (utilização da imagem) ao texto escrito. Explicaremos melhor, utilizando a potencialidade da fotografia como instrumento/método de pesquisa.

A fotografia, como afirmamos anteriormente, vem cada vez mais assumindo o lugar da verdade (objetividade), do real na Sociedade do Espetáculo. Contudo, e contrariamente a esta perspectiva ideológica, acreditamos que a fotografia é uma interpretação da realidade, uma forma de ver/olhar a realidade a partir de referenciais subjetivos ligados à cultura e história do sujeito que a produziu. Claro que a foto/imagem é um meio de "tocarmos" o real, um índice da realidade que pode evocar memórias, representações, mas nunca abarcar uma totalidade da qual ela foi "rasgada" (de onde surgiu), o que lhe confere um caráter lacunar, ou seja, a imagem fotográfica está sempre se completando, e isso irá depender de seu observador.

Assim, o olhar fotográfico ao qual nos referimos está estritamente relacionado ao olhar sintético do "olhar conhecer" (teoria perceptiva) com o "olhar expressão" (teoria expressiva), "que sentindo conhece, conhecendo sente; formando exprime e exprimindo, forma" (BOSI, 1988, p.81) A fotografia se constitui como uma extensão da nossa capacidade de olhar sinteticamente, através de uma técnica e uma linguagem própria. Não fotografamos apenas com nossa máquina, mas sim com toda nossa cultura e nossa visão de mundo (ideológica ou utópica).

As fotografias na pesquisa não são então pensadas como objetos isolados, independentes, mas situadas em um contexto e indelevelmente marcadas por quem as produziu, pelo olhar de quem as "recortou" da realidade.

Uma das principais contribuições da fotografia às Ciências Sociais apontadas por Guran (2000) é que ela nos obriga a uma percepção diferenciada da realidade, do mundo, comparada a outros métodos de pesquisa, nos trazendo informações e conhecimentos que dificilmente obteríamos por outro meio. Tal fato está relacionado à especificidade da imagem fotográfica que capta o detalhe, o instante, congela frações de segundos, exprimindo significados particulares que talvez, no contínuo das ações, não seriam tão perceptíveis ou passíveis de análises, revelando assim a singularidade e transcendência de um momento.

Essa potencialidade da fotografia nos faz lembrar a Sociologia da Vida Cotidiana que, conforme Pais (1886, p.21) estuda "os pequenos nadas do cotidiano"; ou seja, busca encontrar na miséria da vida cotidiana banal, corriqueira, as grandezas do inesperado, 
do acontecimento, da subversão (LEFEBVRE, 1981, citado por SILVA, 2003). Aliás, essa foi a perspectiva teórico-metodológica adotada por Silva que, na pesquisa em Educação Física, trabalhou com a fotografia de forma epistemologicamente articulada com o texto escrito.

Nesse sentido, acreditamos ser preciso ultrapassar o costumeiro uso da fotografia/imagem como ilustração desarticulada e solta pelo texto, ou como simples "enfeite" do trabalho, que sugerem a banalização do seu uso indiscriminado e descomprometido. Pensar na fotografia em pesquisa é pensar sua potencialidade epistemológica e, expressivamente falando, sua relação com os conhecimentos produzidos numa reflexão teóricometodológica que não relegue a fotografia ao plano estritamente instrumental e tecnificador.

Quando utilizamos a fotografia em uma pesquisa de campo, devemos concebê-la como uma forma de ver e pensar o mundo e os sujeitos envolvidos. Isto requer vê-la para além da técnica, não apenas como uma imagem técnica, mas sim levando em consideração toda uma reflexão que não considera a utilização dos instrumentos de pesquisas algo isolado ou desarticulado dos caminhos teóricos e epistemológicos que o pesquisador emprega na sua pesquisa, e na sua forma de produzir conhecimento.

Desta forma, como utilizar a fotografia/imagem em pesquisas de forma não banalizada? Em que medida ela nos ajuda a compreender, analisar e expressar o objeto de estudo?

Os clássicos da Antropologia de Malinowski ${ }^{5}$ e Margareth Mead e Gregory Bateson ${ }^{6}$ já nos trouxeram "pistas", como caminhos possíveis de integrar ao texto verbal o texto visual (fotos), utilizando-os para melhor eficácia narrativa e compreensiva de culturas e processos sociais.

Segundo Samain (1995, p.27),

[...] fica patente que, para Malinowski, o verbal e o pictórico (desenhos, esquemas e fotografias) são cúmplices necessários para elaboração de uma antropologia descritiva aprofundada. Tal osmose é capital para ele. $\mathrm{O}$ texto não basta por si só. A fotografia, também não. Acoplados,

5 Os Argonautas do Pacífico ocidental (publicado em 1922), A vida sexual dos selvagens (publicado em 1929) e Os jardins de coral e suas mágicas (publicado em 1935) - trabalhos sobre os nativos das Ilhas Trobriand que traz sua atividade fotográfica.

6 Balinese Character: uma análise fotográfica (publicado em 1942) - trabalho de campo realizado em Bali. 
inter-relacionados constantemente, então sim, ambos proporcionarão o sentido e a significação.

Sobre Mead e Bateson, temos as constatações de Becker (1996, p.137), para quem:

Buscando novos caminhos, decidiram utilizar-se de fotografias e imagens em movimento para estudar a cultura como elemento incorporado nos mais íntimos detalhes do comportamento. Apresentaram seus resultados daquilo que é, ainda hoje, considerado o mais ambicioso trabalho de fotografia antropológica já publicada: Balinese Character.

De forma bastante didática e acessível de como utilizar fotografias em pesquisa, temos ainda a contribuição de Guran (2000) em que analisa as principais questões teóricas e práticas inerentes à produção e a utilização do que chamou de dois tipos de fotografias possíveis, dentre outras, na pesquisa: a fotografia para descobrir e entender, e a fotografia para contar.

A fotografia feita para descobrir (para obter informação, servindo como ponto de partida) corresponde àquela feita no momento de observação participante em que o pesquisador está se familiarizando com seu objeto de estudo e formulando as primeiras questões com relação a pesquisa de campo. É quando no cotidiano de um campo começamos a perceber algumas coisas, suscitando mais perguntas do que respostas, uma vez que podem destacar o inesperado, imprevisível, abrindo novas compreensões e absorção de um fato.

A fotografia feita para contar (para demonstrar ou enunciar conclusões, servindo como ponto de chegada) surge a partir do domínio e compreensão do objeto de estudo, podendo apresentar (de forma integrada com o texto) as conclusões da pesquisa, ajudando a desenvolver as reflexões que se apóiam nas evidencias, destaques, marcas, apontadas pela fotografia. É produzida, geralmente, quando o pesquisador já consegue identificar os elementos significativos e relevantes para apresentação de sua reflexão.

Nada impede também que as fotografias feitas no momento de "descoberta", depois de uma releitura, possam integrar esse discurso final, transformando-se em fotografias que "contam". Nesta etapa final de produção do relatório de pesquisa, Guran (2000) destaca a importância da conexão entre a linguagem visual e a escrita. Esta articulação foto-texto pode ser: 1) de complementariedade - foto utilizada depois do texto para 
"dar conta" do que foi falado; 2) de encenação ou ilustração representativa - foto antes do texto como ponto de partida para uma reflexão. O importante aqui é deixar clara a necessidade de complementaridade entre texto-visual e texto-escrito na pesquisa científica como predicado de uma narrativa eficaz.

Uma estratégia bastante interessante a ser utilizada com fotografias em pesquisa é a possibilidade de restituição das fotos as pessoas/grupos fotografados. Em entrevistas, conversas com os sujeitos envolvidos, essas fotografias podem ajudar a elucidar perguntas e reflexões em busca de conhecimentos, análises e significações do objeto de estudo. Neste momento, a fotografia pode assumir, algumas vezes, sua natureza emique (GURAN, 2000), isto quer dizer, são as fotografias assumidas pelos grupos, e reveladoras da imagem social que fazem de si próprios, tornando-se elemento importante de análise da identidade social. Por outro lado temos ainda as fotos etique (GURAN, 2000) que são aquelas tiradas pelo pesquisador e são sempre algo, uma hipótese a se confirmar ao longo da pesquisa.

Cabe aqui uma referência a estudo de Costa (2006), também pesquisador do GRUPO DOS AUTORES que, em sua investigação, buscou compreender como indumentária e adereços utilizados por estudantes do ensino médio, além de símbolos comunicacionais, constituem-se também em identidades corporais provisórias. A fotografia foi a forma de registro adotada para o acompanhamento da formação dos grupos e subgrupos, a ocupação de espaços da sala de aula e nos externos a ela, as interações intergrupos, etc. Aos serem devolvidas aos grupos, as fotos serviram de elemento detonador de reflexões sobre os seus "movimentos" coletivos iniciais, os agrupamentos, as acomodações, tendo as roupas e outros elementos da moda como catalisadores destas aproximações e de afastamentos.

Por fim, ainda destacamos a célebre obra de Barthes (1981) “A Câmera Clara", que nos fornece um outro olhar para a análise de fotografias: o olhar vertical, o olhar que procura. Em busca desse olhar perdido, e despindo-se de toda racionalização de sua condição de semiólogo, Barthes neste seu último livro nos deixa um legado importante, se colocando na condição da "infância", não tão domesticado, despido de modelos gerais e teóricos. Assim, destaca o papel latente/ engajado do imaginário social presente em cada um de nós (observadores) e não apenas o olhar da pretensa racionalidade pura. A partir do lugar de observador das fotografias, nos apresenta o studium e punctum da fotografia. 
O studium são aquelas fotografias que nos despertam um interesse geral, nada particular, que conhecemos em suas "cenas", em que investimos nosso saber, nossa cultura, que nos leva sempre a uma "informação clássica". O punctum, pelo contrário, é que vem em nossa direção, saltando ou não dessas cenas, como pontos/detalhes sensíveis de algumas fotografias que nos atingem (BARTHES, 1981).

O punctum não está relacionado com as intenções do fotógrafo, com a cultura do operador, com sua visão de mundo. Ele depende do spectador, de se sentir ferido, pungido por determinada imagem; ao contrário do studium que é uma espécie de saber que permite encontrar o operador e suas intenções, o sentido óbvio das imagens.

Assim, encontramos dois percursos, dois momentos complementares. O primeiro seria a busca da "significação" na fotografia, "a interrogação do studium, em torno desta 'máscara' cultural que toda fotografia oferece e com que se apresenta." (SAMAIN, 1998, p.132) O segundo, seria a busca de "significância", "da essência da fotografia, de seu punctum, esse acaso que, nela, me punge (mas também me mortifica, me fere)" .

Desta maneira, Samain (1998) destaca que Barthes nos remete a um outro olhar, a um olhar vertical, abissal, que procura o detalhe, o fragmento, o punctum, e indaga: "será que seu subjetivismo declarado não se podia contrapor ao 'objetivismo' obsessivo de uma chamada 'observação científica ou antropológica'?" (p. 124). Finalizando seu texto, afirma: "Barthes morreu. Resta-nos entrar na câmera clara." (SAMAIN, 1998, p. 134)

Ainda nos fica a interrogação: será que na condição de pesquisadores-fotógrafos também não existe uma relação de punctum com a realidade que observamos? Talvez não seriam alguns desses detalhes, que eu capto com meu olhar fotográfico sintético (percepção e expressão), um puntum da realidade estudada e que me punge a descobrir?

\section{A imagem/ fotografia na escola}

Há algum tempo é uma de nossas preocupações, como educadores, alertarmos para a necessidade da escola e de práticas pedagógicas comprometidas com uma educação transformadora problematizar junto aos alunos essa "enxurrada" de informações e imagens veiculadas pela mídia. Isto porque, como já apontamos ao esboçar o cenário social, as imagens produzidas vem contribuindo, cada vez mais, para alimentar nosso imaginário e cons- 
truirmos interpretação do mundo. Interpretações essas não isentas de interesses e ideologias do modo de produção dominante, uma vez que, como já afirmou Nichols (1981), as imagens são "construídas" sob prismas ideológicos, e utilizadas eficientemente para manutenção da ordem estabelecida. Assim, precisamos aprender a "ler imagens" enquanto códigos perceptivos predominante na contemporaneidade, como constructos histórico-sociais.

Na medida em que nosso olhar é cada vez mais "colonizado"7 por outros interesses, é necessário trazermos para o processo educativo as imagens midiáticas, como forma de reflexão e educação para/ com a mídia, tornando nossos alunos leitores críticos de imagens.

A fotografia, enquanto imagem presente em várias instâncias comunicacionais (revistas, jornais, TV, publicidade, etc.) pode constituir-se também num importante aliado pedagógico do professor, nas suas três dimensões sugeridas pela mídia-educação (FANTIN, 2006): enquanto objeto de estudo/análise, como ferramenta/instrumento de ensino para apropriação de conhecimentos, e na forma de conteúdo produzido pelos sujeitos/alunos.
Contudo, primeiramente é necessário promover o entendimento de que a foto é uma elaboração carregada de intencionalidades do fotógrafo, ou seja, ela não é simplesmente o resultado de um processo estritamente técnico realizado pela câmera, mas também, a produção de alguém que interpreta e registra uma dada realidade de acordo com suas próprias referências. Desta forma, é preciso considerar que o receptor das imagens fotográficas também faz leituras pessoais, de acordo com suas estruturas de mediações culturais, e de acordo com o puctum que elas podem ou não evocar. Mesmo sendo essa capacidade autônoma e consciente do sujeito, frente à percepção de imagens, cada vez mais limitada e difícil, devido à manipulação das subjetividades na atualidade pela Sociedade do Espetáculo acreditamos ser esta uma brecha para a intervenção pedagógica.

A escola, como "instituição mediadora" (OROZCO, 1993) do processo comunicacional, pode agir reforçando ou re-significando saberes e representações culturalmente internalizadas pelas imagens consumidas pelos alunos. Tarefa essa nada fácil, que exige trabalho

7 Recolhemos aqui a expressão utilizada por Habermas (1987), para quem uma das patologias da modernidade é a "colonização" do mundo vivido (cultura) pelo sistema (mundo do poder, economia, política e outros). 
integrado, multidisciplinar, e conhecimentos técnicos e conceituais que propiciem a abordagem de imagens fotográficas de forma crítica.

Pensando um pouco no caso da Educação Física, a organização de Unidades Temáticas que articulem as especificidades/ conteúdos da disciplina com o trabalho com imagens/fotografias pode então ser pensada como forma de esclarecimento frente a algumas problemáticas e aos discursos hegemônicos encontrados nas "imagensdominantes", como por exemplo: a construção de estereótipos e padrões corporais, esportivização das praticas corporais de movimento, representações do esporte como saúde, sucesso, inclusão, etc.

Trazendo fotos/imagens de jornal, revistas, entre outras mídias, ao cotidiano das aulas, devemos primeiramente deixar evocar os sentido atribuídos às imagens pelos alunos, para depois coletivamente resignificá-los, reconstruí-los sobre uma concepção crítica, conforme sugere o método compreensivo de Ferrés (1994).

É importante também criar "Oficinas de Experiências ${ }^{8}$ Fotográficas", para que através do meio também se possa refletir questões ligadas ao seu uso, suas possibilidades e suas especificidades. Como estratégias, podemos pedir para que os alunos fotografem temas pré-determinados, como forma de revelar seus discursos e suas significações, que muitas vezes, apresentam-se contaminados com o modo de ver dominante. Nesse sentido, é necessário problematizar o material (fotos) e a própria experiência coletivamente, como forma de construir outros olhares possíveis e desejáveis.

Foi nesta perspectiva que se desenvolveu o estudo de Oliveira e Pires (2005), uma pesquisa-ação que propôs e realizou, numa escola pública de Florianópolis, Oficina de Experiências com o Olhar (fotografia e video), que resultaram em narrativas multimídias (discursivas e imagéticas), desenvolvidas por alunos participantes, sobre o cotidiano da cultura corporal de movimento escolar e extra-escolar.

\section{Palavras finais}

Não foi nossa intenção com este ensaio fornecer "receita de bolo" ou "guia para de utilização da imagem/fotografia" na Educação Física; desejamos somente destacar

8 Compreendido na perspectiva da formação cultural frankfurtiana, cabe destacar enquanto embasamento o entendimento de Benjamim para quem a experiência formativa (Erfahrung) ultrapassa ou supera a mera vivência (Erlebnis). 
e aprofundar algumas reflexões e possibilidades de se pensar este instrumento técnico-cultural como um possível "aliado" tanto na pesquisa quanto nos processos pedagógicos que não se negam a reconhecer a linguagem visual e imagética como constituinte importante das relações e percepções da contemporaneidade, inclusive, sobre a cultura de movimento..

Como usá-las? Com que interesses? São as principais reflexões que deixamos como desafio a ser assumido por pesquisadores e professores, em contraposição ao Mundo-Imagem, à banalização da imagem, especialmente a fotográfica, na Sociedade do Espetáculo.

\section{Referências}

ADORNO, T. W.; HORKHEIMER, $M$. Dialética do esclarecimento. Rio de Janeiro: Zahar, 1985.

BARTHES, R. A Câmera Clara. Lisbôa: Edições 70, 1981.

BECKER, H. Balinese Character: uma análise fotogrpafica - Gregory Bateson e Margaret Mead. Cadernos de Antropologia e Imagem. n.2 Antropologia e fotografia. Rio de Janeiro: UERJ, NAI, 1996.

BITENCOURT, F. G. Fotografia na era digital: produção, protagonismo e performance. Problemas para a Educação Física/Ciências do Esporte. Congresso Brasileiro de Ciências do Esporte, 16, Anais... Salvador: CBCE, setembro/2009. (disponíveis em www.cbce.org.br) BOSI, A. Fenomenologia do Olhar. In: NOVAES, Adalto. (org.). $\mathbf{O}$ Olhar. São Paulo: Companhia das Letras, 1988.

BOURDIEU, P. Sobre a televisão. Rio de Janeiro: Zahar, 1997.

COSTA, A.G. Moda/indumentária em culturas juvenis: símbolos de comunicação e formação de identidades corporais provisórias em jovens de ensino médio. Dissertação (Mestrado em Educação Física). Florianópolis: PPGEF/UFSC, 2006.

DEBORD, G. A sociedade do espetáculo. Rio de Janeiro: Contraponto, 1997.

$\mathrm{ECO}, \mathrm{U}$. Viagem à irrealidade cotidiana. Rio de Janeiro: Nova Fronteira, 1984.

FANTIN, M. Mídia-educação: conceitos, experiências, diálogos Brasil-Itália. Florianópolis: Cidade Futura, 2006.

FERRÉS, J. Televisão e educação. Porto Alegre: Artes Médicas, 1994.

GURAN, M. Fotografar para descobrir/ fotografar para contar. In: Cadernos de Antropologia e Imagem. Rio de Janeiro: UERJ, v.10, n.1, p.155-156.

HABERMAS, J. Teoria de la acción comunicativa. Madri: Taurus, 1987 (Tomos I e II). 
KEHL. M. R. O espetáculo como meio de subjetivação. In: $\mathrm{BUCCl}$, E.; KEHL, M. R. (orgs.) Videologias: ensaios sobre televisão. São Paulo: Boitempo, 2004.

NICHOLS, Bill. Ideology and the Image. Bloomington: Indiana University Press, 1981.

OROZCO, G. G. Hacia una dialectica de la recepción televisiva: la la estructuración de estrategias por los televidentes. In: Comunicação \& Política na América Latina. ano 8, v. 22 a 25, p.57-73,1993.

OLIVEIRA, M. R. R.; PIRES, G. L. O Primeiro Olhar: experiência com imagens da Educação Física escolar. Revista Brasileira de Ciências do Esporte. CBCE: v. 26 , n. 2, p. 117-133, janeiro2005.

PAIS, J.M. Paradigmas sociológicos na análise da vida quotidiana. Análise Social, v.22, n.90, 1986.
PIRES, G.L. Educação Física e o discurso midiático: abordagem crítico-emancipatória. Ijuí: Ed. UNIJUI, 2002.

SAMAIN, E. Um retorno à Câmera Clara: Roland Barthes e a antropologia visual. In: O Fotográfico. São Paulo: HUCITEC, 1998. (p.121-134). "Ver" e "Dizer" na tradição etnográfica: Bronisslaw Malinowski e a fotografia. Horizontes Antropológicos. n.2, p.19-48., 1995.

SILVA, M. R. Trama doce-amarga: (exploração do) trabalho infantil e cultura lúdica. São Paulo: HUCITEC, 2003.

SONTAG, S. O mundo-imagem. In: SONTAG, Susan. Sobre Fotografia. São Paulo: Companhia das Letras, 2004.

Recebido: agosto/2010. Aprovado: outubro/2010. 